\title{
Cardiotoxicity screening: a review of rapid-throughput in vitro approaches
}

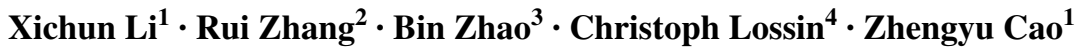

Received: 22 July 2015 / Accepted: 18 November 2015 / Published online: 16 December 2015

(C) Springer-Verlag Berlin Heidelberg 2015

\begin{abstract}
Cardiac toxicity represents one of the leading causes of drug failure along different stages of drug development. Multiple very successful pharmaceuticals had to be pulled from the market or labeled with strict usage warnings due to adverse cardiac effects. In order to protect clinical trial participants and patients, the International Conference on Harmonization published guidelines to recommend that all new drugs to be tested preclinically for hERG $\left(\mathrm{K}_{\mathrm{v}} 11.1\right)$ channel sensitivity before submitting for regulatory reviews. However, extensive studies have demonstrated that measurement of hERG activity has limitations due to the multiple molecular targets of drug compound through which it may mitigate or abolish a potential arrhythmia, and therefore, a model measuring multiple ion channel effects is likely to be more predictive. Several phenotypic rapid-throughput methods have been developed to predict the potential cardiac toxic compounds in the early stages of drug development using embryonic stem cells- or
\end{abstract}

Bin Zhao

binzhao@rcees.ac.cn

Zhengyu Cao

zycao1999@hotmail.com

1 State Key Laboratory of Natural Medicines and Jiangsu Provincial Key Laboratory for TCM Evaluation and Translational Development, China Pharmaceutical University, 639, Longmian Ave, Jiangning District, Nanjing 211198, People's Republic of China

2 Department of Molecular Biosciences, School of Veterinary Medicine, University of California, Davis, Davis, CA 95616, USA

3 Research Center for Eco-Environmental Sciences, Chinese Academy of Sciences, Beijing 100085, China

4 Department of Neurology, University of California, Davis, Sacramento, CA 95817, USA human induced pluripotent stem cell-derived cardiomyocytes. These rapid-throughput methods include microelectrode array-based field potential assay, impedance-based or $\mathrm{Ca}^{2+}$ dynamics-based cardiomyocytes contractility assays. This review aims to discuss advantages and limitations of these phenotypic assays for cardiac toxicity assessment.

Keywords Cardiotoxicity - Rapid throughput . hERG · Automated patch clamp · Microelectrode array · Fluorescence plate reader

$\begin{array}{ll}\text { Abbreviations } \\ \text { AP } & \text { Action potential } \\ \text { APC } & \text { Automated patch clamping } \\ \text { ESC } & \text { Embryonic stem cell } \\ \text { FPD } & \text { Field potential duration } \\ \text { FLIPR } & \text { Fluorescent imaging plate reader } \\ \text { iPSC } & \text { Induced pluripotent stem cell } \\ \text { IC }_{50} & \text { Half-maximal inhibitory concentration } \\ \mathrm{K}_{\mathrm{v}} & \text { Voltage-gated potassium channels } \\ \text { LQTs } & \text { Long-QT syndrome } \\ \text { MEA } & \text { Microelectrode array } \\ \mathrm{Na}_{\mathrm{v}} & \text { Voltage-gated sodium channels } \\ \text { RTCA } & \text { The real-time cell analyzer } \\ \text { TdP } & \text { Torsade de pointes }\end{array}$

\section{Introduction}

\section{Cardiotoxicity is a leading cause for drug failure}

Cardiotoxicity is one of the leading causes for failure, during drug development as well as after a compound has been approved for therapy. Between 1990 and 2013, a total of 81 drugs had to be taken off of the market in the USA, Europe, 
and Asia, due to treatment-emergent effects, with 16 of the compounds producing cardiac arrhythmias. Moreover, since 1997, cardiotoxicity-related withdrawal has dramatically increased from 5.1 to $33.3 \%$ (Table 1-MacDonald and Robertson 2009; Qureshi et al. 2011). This includes compounds seeking to rectify cardiovascular problems such as the antiarrhythmic agent encainide (Apostolakis et al. 2013) or the hypertensive mibefradil (Huang et al. 2015), but also drugs with entirely different indication, for example the antihistamine terfenadine (Braam and Mummery 2010; Hondeghem et al. 2011; Sirenko et al. 2014) or the gastroprokinetic cisapride (Sirenko et al. 2014; Wilhelms et al. 2012). In some cases, the drugs were not withdrawn, but amended with cautionary notes informing about possible adverse cardiac effects, as was the case with the antidiabetic rosiglitazone, where a meta-analysis had revealed increased incidence of myocardial infarction and death (Sager et al. 2015). While still available in the US market, rosiglitazone is now under strict scrutiny, in that it can only be prescribed by certified doctors and purchased through special pharmacies, which led to a dramatic drop in prescriptions in 2012, amounting to only $\sim 0.4 \%$ of what had been seen in 2006.

Early-stage drug discovery commonly uses mechanismbased, high-throughput screening, which allows candidate identification from compound libraries comprising $>100,000$ different molecules. Stringent toxicity analyses follow, but $20-50 \%$ of all advanced candidates have to be

Table 1 Drugs withdrawn due to arrhythmia (1990-2010)

\begin{tabular}{|c|c|c|c|c|}
\hline Drug name & Usage & Year withdrawn & Remarks & References \\
\hline Encainide (Enkaid) & Antiarrhythmia & 1991 (US, UK) & QT prolongation ${ }^{\mathrm{a}}$ & Echt et al. (1991) \\
\hline Terodiline (Micturin) & Antispasm & 1991 (Germany, UK) & $\begin{array}{l}\text { QT prolongation, torsade de } \\
\text { pointes }(\mathrm{TdP})^{\mathrm{b}}\end{array}$ & Thomas et al. (1995) \\
\hline Dexfenfluramine (Redux) & Antiobesity & 1997 (US, EU, UK) & $\begin{array}{l}\text { QT prolongation, } \\
\text { tachycardia, arrhythmia }\end{array}$ & Weissman et al. (1998) \\
\hline $\begin{array}{l}\text { Terfenadine (Seldane/Tri- } \\
\text { ludan) }\end{array}$ & Antihistamine & 1997 (US, France) & $\begin{array}{l}\text { QT prolongation, ventricular } \\
\text { tachycardia }\end{array}$ & Roy et al. (1996) \\
\hline Mibefradil (Posicor) & Antihypertension & 1998 (US, EU) & $\begin{array}{l}\text { QT prolongation, fatal } \\
\text { arrhythmia }\end{array}$ & $\begin{array}{l}\text { Bezprozvanny and Tsien } \\
\text { (1995) }\end{array}$ \\
\hline $\begin{array}{l}\text { Sertindole (Serdolect/Ser- } \\
\text { lect) }\end{array}$ & Antipsychotic & 1998 (EU) & $\begin{array}{l}\text { QT prolongation, risk of } \\
\text { TdP }\end{array}$ & Karamatskos et al. (2012) \\
\hline Astemizole (Hismanal) & Antihistamine & 1999 (US) & $\begin{array}{l}\text { QT prolongation, risk of } \\
\text { TdP }\end{array}$ & Zhou et al. (1999) \\
\hline Grepafloxacin (Raxar) & Antibacterial & 1999 (Worldwide) & QT prolongation & Roy et al. (1996) \\
\hline Cisapride (Propulsid) & Gastroprokinetic agent & 2000 (US) & $\begin{array}{l}\text { QT prolongation, risk of } \\
\text { TdP }\end{array}$ & Durdagi et al. (2014) \\
\hline $\begin{array}{l}\text { Sparfloxacin (Spacin/ } \\
\text { Zagam) }\end{array}$ & Antibacterial & 2001 (US) & $\begin{array}{l}\text { QT prolongation and photo- } \\
\text { toxicity }\end{array}$ & Agarwal et al. (2014) \\
\hline $\begin{array}{l}\text { Levomethadylacetate } \\
\text { (OrLAAM) }\end{array}$ & $\begin{array}{l}\text { Treatment of opioid } \\
\text { dependence }\end{array}$ & 2003 (US) & $\begin{array}{l}\text { QT prolongation, cardiac } \\
\text { arrest, risk of TdP }\end{array}$ & Hamilton et al. (2013) \\
\hline $\begin{array}{l}\text { Thioridazine (Mellaril/Mel- } \\
\text { leril) }\end{array}$ & Antipsychotic & 2005 (Germany, UK) & QT prolongation & $\begin{array}{l}\text { Fenton et al. (2007), Fornaro } \\
\text { et al. (2002), Keks et al. } \\
\text { (1994) }\end{array}$ \\
\hline Clobutinol (Clobutinol) & Cough suppressant & 2007 (Germany) & $\begin{array}{l}\text { Ventricular arrhythmia, QT } \\
\text { prolongation }\end{array}$ & Bellocq et al. (2004) \\
\hline $\begin{array}{l}\text { Propoxyphene (Darvocet/ } \\
\text { Darvon) }\end{array}$ & Analgesic & 2010 (Worldwide) & $\begin{array}{l}\text { QT prolongation, elevated } \\
\text { risk of MI and stroke }\end{array}$ & $\begin{array}{l}\text { Becquemont et al. (2014), } \\
\text { Butola and Rajagopal } \\
\text { (2015) }\end{array}$ \\
\hline Rosiglitazone (Avandia) & Antidiabetic drug & 2010 (EU) & $\begin{array}{l}\text { Cardiac arrhythmias, risk of } \\
\text { MI and death }\end{array}$ & $\begin{array}{l}\text { Chen et al. (2012), Nissen and } \\
\text { Wolski (2007) }\end{array}$ \\
\hline $\begin{array}{l}\text { Sibutramine (Reductil/ } \\
\text { Meridia) }\end{array}$ & Anorexiant & 2010 (Worldwide) & $\begin{array}{l}\text { QT prolongation, risk of MI } \\
\text { and stroke }\end{array}$ & $\begin{array}{l}\text { Abe et al. (2015), Hassan and } \\
\text { El-Gharib (2015), Hayes } \\
\text { et al. (2015), Khorassani } \\
\text { et al. (2015) }\end{array}$ \\
\hline
\end{tabular}

$M I$ myocardial infarction

${ }^{a}$ Refers to an abnormally long-QT interval in electrocardiographic analyses, indicating abnormalities in ventricular

b Ventricular tachycardia associated with QT prolongation with characteristic waxing and waning of the QRS amplitude de-/repolarization 
abandoned due to unwanted effects, even in the late stages of drug development (Kola and Landis 2004). Only 1 in 5000-10,000 screened chemicals reaches the market, with an associated cost of \$1-2 billion for development and a 12- to 15-year commitment (Boverhof and Zacharewski 2006). The associated economic risk can be significantly reduced if compounds with therapeutic but toxic properties are recognized early. Since cardiotoxicity is the leading cause for drug failure, emphasizing screens for cardiac side effects is especially helpful (Brana and Tabernero 2010; Doherty et al. 2015; Du et al. 2011; Stoelzle et al. 2011; Su et al. 2011).

\section{The role of hERG in cardiotoxicity screening}

Cardiac contraction is initiated by the cardiac action potential (AP), which involves the harmonious cooperation of several distinct ion channels (Fig. 1). As in neurons, voltage-gated sodium $\left(\mathrm{Na}_{\mathrm{v}}\right)$ channels stand at the beginning of all activity: they allow for influx of $\mathrm{Na}^{+}$ions $\left(I_{\mathrm{Na}}\right)$, which is responsible for the initial, rapid depolarization (phase 0 ). The change in the membrane potential opens voltagegated potassium channels carrying a transient outward current $\left(I_{\mathrm{to}}\right)$ that begins to repolarize the cardiomyocyte (phase 1). However, opening of L-type $\mathrm{Ca}^{2+}$ channels $\left(I_{\mathrm{Ca}}\right)$ and rapid as well as slow delayed rectifier $\mathrm{K}^{+}$channels $\left(I_{\mathrm{Kr}}\right.$, $I_{\mathrm{Ks}}$ ) temporarily plateau repolarization (phase 2 ), which is only overcome once additional rectifier $\mathrm{K}^{+}$channels open (rapid delayed, slow delayed, and inward, mediating $I_{\mathrm{Kr}}, I_{\mathrm{Ks}}$, and $I_{\mathrm{K} 1}$, respectively) that fully repolarize the cell (phase 3-Abriel et al. 2015). The human Ether-à-go-gorelated gene (hERG, official gene name $\mathrm{KCNH} 2$, which encodes the protein $\mathrm{K}_{\mathrm{v}} 11.1$ ) mediates the repolarizing $I_{\mathrm{Kr}}$ current in the cardiac AP during phase 2 and phase 3. Loss of hERG channel function by pharmacological inhibition or genetic mutation has been shown to delay the AP repolarization and widen the ventricular $\mathrm{AP}$, which is the underlying physiological abnormality in long-QT syndrome (Fig. 1a), a disorder associated with syncope, seizures, and even sudden death (Curran et al. 1995; Danker and Moller 2014; Priest et al. 2008; Wible et al. 2005). A great number of previously withdrawn drugs (Table 1) have been found to induce arrhythmia through hERG channel blockade. Interestingly, many of these are small molecules carrying hydrophobic rings and a hydrogen bond acceptor that are critical for interaction with hERG (Villoutreix and Taboureau 2015). Ligand-based hERG channel modeling furthermore revealed three major factors that elevate a compound's likelihood of blocking hERG, which include (1) a positively charged nitrogen atom, (2) high lipophilicity, and (3) the absence of negatively charged oxygen atom (Doddareddy et al. 2010; Villoutreix and Taboureau 2015). These interaction characteristics are tightly connected to

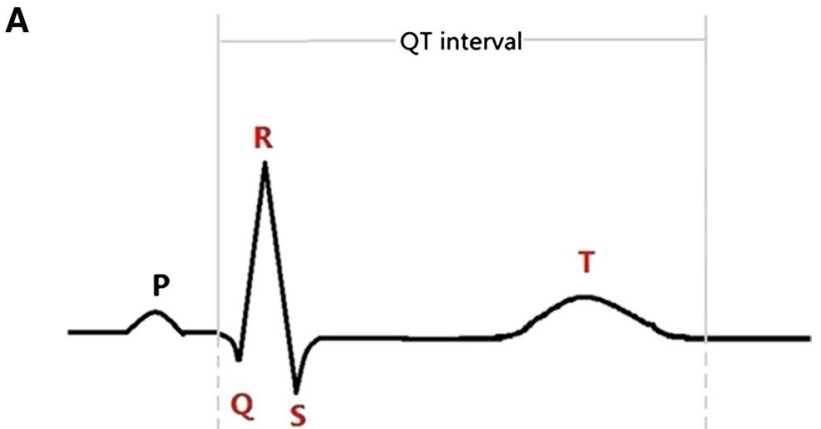

B

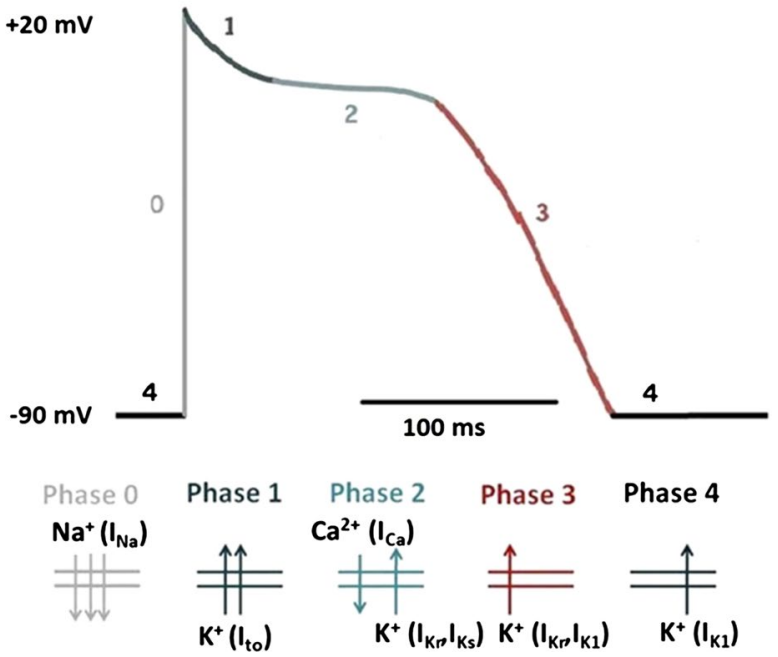

Fig. 1 Schematic alignment of a whole-heart electrocardiogram (ECG) and action potential of a cardiac myocyte. a Schematic presentation of a normal ECG trace. Ventricular myocyte depolarization correlates with the start of the QRS complex, whereas repolarization is reflected by the T wave (Bridal et al. 2010). The QT interval (healthy: $350-440 \mathrm{~ms}$ ) refers to the time from the beginning of the QRS complex to the end of the $\mathrm{T}$ wave. Genetic predisposition or drug administration can delay the repolarization phase of the action potential, which reflects as prolongation of the QT interval to unhealthy levels (commonly $>500 \mathrm{~ms}$ ), hence the name "long-QT syndrome". b Schematic presentation of an action potential of a cardiac myocyte. The rapid entry of $\mathrm{Na}^{+}$through voltage-gated sodium channels $\left(I_{N a}\right)$ is responsible for rapid, Phase 0 , depolarization. The opening of transient potassium channels $\left(I_{t o}\right)$ mediates rapid, phase 1, repolarization, which is followed by the opening of L-type calcium channels $\left(I_{C a}\right)$ and slow delayed rectifier potassium channels $\left(I_{\mathrm{Ks}}\right)$ that are responsible for subsequent action potential plateau (phase 2). The opening of the potassium channels, including those mediating the rapid delayed rectifier current $\left(I_{\mathrm{Kr}}\right)$, slow delayed rectifier current $\left(I_{\mathrm{Ks}}\right)$, and the inward rectifier $\mathrm{K}^{+}$current $\left(I_{\mathrm{K} 1}\right)$, ultimately repolarizes the cardiomyocyte during phase 3 . The final phase of the action potential signals a return of the membrane potential to its baseline value near $-90 \mathrm{mV}$ (phase 4)

structure: hERG channels are homotetramers of four identical $\alpha$-subunits, each comprising six $\alpha$-helical transmembrane segments (S1-S6). Voltage sensitivity is mediated by the voltage sensor domain (S1-S4), more specifically positively charged lysine and arginine in $\mathrm{S} 4$ that move in response to the membrane potential change. Segments S5 
and $\mathrm{S} 6$ form the pore that allows $\mathrm{K}^{+}$ions cross to lipid bilayer. A lengthy S5-P linker that contains an amphipathic helix (the turret helix) and a selectivity filter loop is also present in these segments. Both the N-terminus and the C-terminus locate to the intracellular side (Stansfeld et al. 2007). Unlike most other $K_{v}$ channels, hERG channels lack two kinking proline residues that restrict the channel's aqueous volume. The consequently larger hERG channel cavity is more accommodating, allowing comparatively large drugs to enter and interfere with $\mathrm{K}^{+}$conduction (Mitcheson 2003; Recanatini et al. 2005). In addition, unlike most voltage-gated $\mathrm{K}_{\mathrm{v}}$ channels where the inner helices are lined by aliphatic isoleucine or valine residues, hERG channels have two aromatic residues (Tyr652 and Phe656 in the S6 domain) which are important for the binding of cisapride (Chen et al. 2002; Mitcheson et al. 2000), terfenadine (Mitcheson et al. 2000), quinidine (Lees-Miller et al. 2000; Sanchez-Chapula et al. 2003), and chloroquine (Sanchez-Chapula et al. 2002). The sensitivity for blocking hERG channel activity resulting from Phe656 binding was linearly correlated with the hydrophobicity of the structure (Fernandez et al. 2004). In addition to Tyr652 and Phe656, a number of other amino acid residues, such as Ile647 in the S6 segment (quinidine, E-4031 and terfenadine-Ishii et al. 2001) as well as Ser620 (dofetilide-Ficker et al. 1998), Thr623, Ser624, and Val625 in the P helix (vesnarinone-Kamiya et al. 2001), have been identified as critical for drug binding. Rather than directly inhibiting hERG, some drugs were also found to alter hERG trafficking (Dennis et al. 2012; Villoutreix and Taboureau 2015). The combination of broadly distributed binding sites and the susceptibility to trafficking modulation explains why many structurally diverse small molecules can affect the hERG channel activity and trigger long-QT syndrome.

The challenge in screening for adverse cardiac effects is that the most informative screening methods use animal or ex vivo modeling, which is distinctly low throughput and costly, and it requires large compound quantities. It is, therefore, desirable to identify approaches that combine strong prediction power for cardiotolerability with experimental convenience. To that end, hERG screening offers itself, owing to the channel's tight connection to pharmacologically induced long-QT syndrome and torsades de pointes (or simply, "torsade") (Curran et al. 1995; Danker and Moller 2014; Priest et al. 2008; Wible et al. 2005). Based on the 2002 recommendation by the International Conference on Harmonization (Danker and Moller 2014; Doherty et al. 2015), hERG testing has been adopted for all new drugs prior to regulatory review (Dorn et al. 2005; Giacomini et al. 2015; Guthrie et al. 2005; Huang et al. 2010), which must include direct (i.e., current modulation) as well as indirect (e.g., trafficking) effects on hERG channel function (Wible et al. 2005). To that end, it is useful to first employ in silico analyses that may help identify possible problem molecules; several Web sites offer these services, including Pred-hERG (http://labmol.farmacia.ufg.br/ predherg), Tox-Comp.net (http://www.toxcomp.net/), and ACD-/I-Lab (https://ilab.acdlabs.com/iLab2/index.php) (Villoutreix and Taboureau 2015). In addition, chemogenomics databases such as ChEMBL (Bento et al. 2014), PubChem (Wang et al. 2014), and ChemProt (Kim Kjaerulff et al. 2013) can help narrow the compound candidate list based on chemical similarity to known hERG interacting agents. There are also target prediction Web services such as the SEA search tool (Keiser et al. 2007), PASS (Filz et al. 2008), Swiss Target Prediction (Gfeller et al. 2014), HitPick (Liu et al. 2013), SuperPred (Nickel et al. 2014), and admetSAR (Cheng et al. 2012; Villoutreix and Taboureau 2015). There is, hence, an abundance of resources that can first-level filtering for hERG channel interaction.

Of course, while hERG screening is an efficient way of identifying potential for cardiac adverse effects, it is not wholly predictive. One preclinical analysis found that only $55 \%$ of confirmed hERG inhibitors $\left(\mathrm{IC}_{20} \leq 3 \mu \mathrm{M}\right)$ prolonged the cardiac action potential by more than $10 \%$ (Lu et al. 2008). Similarly, lack of hERG activity is no certain indicator of cardiac tolerability. The alpha-1 blocker alfuzo$\sin$, for example, has little effect on hERG, but it delays cardiac repolarization through increased sodium channel activity, which results in long-QT syndrome (Navarrete et al. 2013). The need for more reliable, rapid-throughput prediction of cardiotoxicity has prompted the development of several new in vitro technologies to help detect adverse cardiac effects in the early stages of the drug development through the use of automated planar patch clamping, microelectrode arrays (MEA), real-time cell analyzers (RTCAs), and fluorescence-based screens (Benay et al. 2015; Elkins et al. 2013; Numann and Negulescu 2001; Su et al. 2011). In this review, we summarize these new methods for cardiotoxicity testing and discuss their advantages and disadvantages.

\section{Non-hERG drug targets in cardiac electrophysiology}

Cardiotoxicity is frequently related to abnormal excitation of the heart, which, viewed broadly, is the result of neuronal input, cardiac conduction (involving the sinoatrial/ atrioventricular nodes and the bundle branches), and cardiomyocyte contraction. As a self-excitatory organ with autonomous rhythmic activity, the heart does not rely on external input to maintain its basic functionality, which may explain why agents affecting neuronal input and cardiac conduction are less likely to precipitate clinical issues. Significant problems arise, however, when (left) ventricular contraction is compromised, as this has direct impact on systemic blood delivery (Cardinale et al. 2013; Keating and Sanguinetti 2001; Zaniboni et al. 2000). 
Under certain circumstances, cardiac excitation can become abnormal, which can lead to arrhythmias. Regardless of whether the heart beat is abnormally slow or fast (i.e., bradycardia and tachycardia, respectively), syncope and death are possible outcomes (Baudenbacher et al. 2008; Huikuri et al. 2001, 2009; Keating and Sanguinetti 2001). Because the ventricles provide the mechanics that move the blood through the system, ventricular arrhythmias are clinically particularly problematic, examples being the aforementioned torsade and ventricular fibrillation (Keating and Sanguinetti 2001; Maeno et al. 2009; Simpson et al. 2009). Epidemiological studies have revealed that gain or loss of function of different ion channels can alter cardiac action potential properties and contribute to arrhythmia susceptibility (Beattie et al. 2013; Burashnikov and Antzelevitch 2003; Cheng et al. 2003; Frea et al. 2015; Kurtzwald-Josefson et al. 2014; London et al. 2007; McNair et al. 2004; Medeiros-Domingo et al. 2007; Nabel 2003; Pfeufer et al. 2005; Schmitt et al. 2014; Splawski et al. 2004; Steffensen et al. 2015; Tester et al. 2005). Heritable dysfunction of the voltage-gated sodium $\left(\mathrm{Na}_{\mathrm{v}}\right)$ channel $\mathrm{Na}_{\mathrm{v}} 1.5$ (gene name: $S C N 5 A$ ), for example, has been associated with long-QT (LQT3) and Brugada syndrome (Giudicessi and Ackerman 2013; Miller et al. 2014). Voltage-gated potassium $\left(\mathrm{K}_{\mathrm{v}}\right)$ channels are also involved; loss of $\mathrm{K}_{\mathrm{v}}$ channel conductance results in action potential prolongation and long-QT syndrome, while $\mathrm{K}_{\mathrm{v}}$ channel gain-of-function gives rise to an abbreviated cardiac action potential and short-QT syndrome (Schmitt et al. 2014), and modulation of aforementioned hERG channels, of course, is a primary cause for cardiac drug complications. As carriers of $I_{\mathrm{Kr}}$, which mediates cardiomyocyte repolarization (Priest et al. 2008), the hERG channel, mores specifically its block, has strong ties to long-QT syndrome, ventricular arrhythmia, and sudden cardiac death (Sanguinetti and Tristani-Firouzi 2006). In addition to $\mathrm{Na}_{\mathrm{v}}$ and $\mathrm{K}_{\mathrm{v}}$ channels, gain-of-function mutations on $\mathrm{Ca}_{\mathrm{V}} 1.2$ (calcium channel subtype 1.2) have been found to produce Timothy syndrome (Splawski et al. 2004, 2005). RyR2 point mutation-related aberrant diastolic $\mathrm{Ca}^{2+}$ leak from sarcoplasmic reticulum contributes to the formation of delayed after-depolarization, leading to heart failure and catecholaminergic polymorphic ventricular tachycardia (Blayney and Lai 2009). Clearly, ion channels of the heart's electrophysiological apparatus constitute potential targets in cardiotoxicity, which provides the basis for many in vitro methods attempting to predict cardiac drug toxicity.

\section{Rapid-throughput cardiotoxicity screening methods}

\section{Fluorescence-based hERG assays}

The hERG channel carries the rapid delayed rectifier $\mathrm{K}^{+}$ current, which is a common player in abnormalities of the QT interval and in ventricular arrhythmia (Sanguinetti and Tristani-Firouzi 2006). As previously discussed, druginduced inhibition of $\mathrm{hERG}$ has good prediction value for cardiotoxicity. Several assays take advantage of this correlation, providing indirect information about hERG targeting through radioligand binding (Cheng et al. 2003) and $\mathrm{Rb}^{+}$efflux (Ding et al. 2006), or by directly assessing a substance's impact on hERG current using automated patch clamping (Bridgland-Taylor et al. 2006). More recently, another in vitro rapid-throughput method was added to this list, which exploits the hERG channel thallium $\left(\mathrm{Tl}^{+}\right)$ conductance (Xia et al. 2011). Cells are loaded with a $\mathrm{Tl}^{+}$sensitive dye. Upon hERG channel opening, $\mathrm{Tl}^{+}$permeates down its concentration gradient into the cell, where it interacts with the dye to generate a fluorescent signal. A reduction in $\mathrm{Tl}^{+}$fluorescence suggests hERG blockade (Huang et al. 2010; Xia et al. 2011). Because the same assay is amenable to other $\mathrm{K}^{+}$channels, it has been successfully used to identify modulators of $\mathrm{K}_{\mathrm{v}} 7.2, \mathrm{~K}_{\mathrm{v}} 7.3$, Kir2.1 (Beacham et al. 2010), $\mathrm{K}_{\mathrm{v}} 7.4$ (Li et al. 2011), and $\mathrm{Ca}^{2+}$. activated $\mathrm{K}^{+}$channels (Jorgensen et al. 2013). The major advantage of this approach is its experimental convenience, permitting use of 96-, 384-, and even 1536-well formats, as well as its relatively low running cost.

To validate whether $\mathrm{Ti}^{+}$influx is a reliable assay for predicting hERG channel blockade, experiments were set up, side-by-side, to compare each assay's sensitivity for hERG modulation, including $\left[{ }^{3} \mathrm{H}\right]$-dofetilide binding, $\mathrm{Tl}^{+}$influx using FLIPR ${ }^{\mathrm{TM}}$ technology, and automated patch clamping (Huang et al. 2010). The study showed that, on average, the $\mathrm{IC}_{50}$ values generated from automated patch clamping were markedly lower, reaching only $1 / 5_{\text {th }}$ and $1 / 17$ th of the values produced with $\mathrm{Tl}^{+}$influx and $\left[{ }^{3} \mathrm{H}\right]$-dofetilide binding, respectively (Huang et al. 2010; Priest et al. 2008). Some of the tested compounds (e.g., ouabain, phenytoin, venlafaxine, and amantadine) produced false-negative data in $\mathrm{Tl}^{+}$influx assay, while false-positive data were absent (Huang et al. 2010). Data from $\mathrm{Tl}^{+}$influx, therefore, must be interpreted with caution. The assay has its advantages, in that it is cost-effective and rapid, generating up to 50,000 data points per day (where one data point informs on the effect of one compound at a single concentration; more data points per day, therefore, equal higher throughput). However, it cannot reliably predict hERG inhibition, especially for those compounds at low potency, which limits its utility to the elimination of compounds with relatively strong hERG inhibition during the early stages of drug development.

Another option to assess hERG modulation is the deployment of voltage-sensitive, fluorescent dyes. The underlying principle is that $\mathrm{K}^{+}$channel opening can lead to hyperpolarization. Potassium channel inhibition, conversely, pushes the cell in the depolarizing direction; all of 
which can be visualized with voltage-sensitive dyes such as the FLIPR membrane potential dye (FMP). Cells stably transfected with hERG and loaded with FMP showed that this technology requires compound concentrations 5 times higher than the detection limit established in automated patch clamping, which translates into a significant risk for false negatives $(\sim 12 \%$ in this study-Dorn et al. 2005). The advantages and disadvantages of fluorescent dye technology, therefore, are similar to what has been discussed above for $\mathrm{Tl}^{+}$influx analyses: low cost point and rapid data generation (again up to 50,000 data points/day), albeit with the limitation that only comparatively potent hERG inhibitors are detected. Because of its screening power and its well-defined shortcomings, voltage-sensitive fluorescent dye assays have been adopted as a standard in the Comprehensive In Vitro Proarrhythmia Assay (CIPA) pilot study organized by the ILSI Health and Environmental Sciences Institute (Sager et al. 2014). It should be emphasized that $\mathrm{Tl}^{+}$permeability and membrane potential changes are highly unspecific changes that must be assessed under heterologous expression (e.g., in HEK or CHO cells) to ensure that the observed effect is not mediated through a non-hERG target (Cao et al. 2014). This brings with it the concerns common for analyses employing heterologous expression. The biophysical properties of hERG behavior in these systems are highly similar, but not identical, to what is seen endogenously. Deactivation of hERG channels, for example, is significantly faster when they are assessed in their natural cardiomyocyte environment (Sanguinetti and Tristani-Firouzi 2006), which may further impact the prediction reliability of these assays (Table 2).

\section{Automated patch clamping}

While hERG channel blockade obviously plays a pivotal role in unwanted cardiac events, various other channels contribute to the cardiac action potential, and their modulation is similarly prone to trigger long-QT syndrome (Beattie et al. 2013; Liu and Trudeau 2015; Medeiros-Domingo et al. 2007; Moric-Janiszewska et al. 2004; Schmitt et al. 2014; Zhang et al. 2012). The gold standard in measuring the compound's effect on ion channel behavior is manual patch clamping (Hamill et al. 1981). This technique, while extremely sensitive, is also immensely time-consuming, labor-intensive, and technically challenging, which limits its usefulness for rapid-throughput cardiotoxicity screening. The last decade has seen a proliferation of platforms that automate patch clamping, and the technology has made

Table 2 Technical summary of assays

\begin{tabular}{|c|c|c|c|c|c|c|}
\hline Assay type $^{a}$ & Platform & Cell type & Well format & Sampling rate & Consumable cost ${ }^{\mathrm{b}}$ & $\begin{array}{l}\text { Subacute } \\
\text { measurement }\end{array}$ \\
\hline \multicolumn{7}{|c|}{ Target-based assay (hERG) } \\
\hline $\mathrm{Tl}^{+}$influx ${ }^{\mathrm{c}}$ & FLIPR & Stable hERG lines & $96,384,1536$ & $8 \mathrm{~Hz}$ & $\begin{array}{l}\text { Clear-bottom, black well } \\
96 \text { or } 384 \text {-well plate }(\sim \$ 5 / \\
\text { plate })\end{array}$ & No \\
\hline hERG channel current ${ }^{\mathrm{d}}$ & APC & Stable hERG lines & 96,384 & $10 \mathrm{kHz}$ & PatchPlate $(\sim 400 /$ plate $)$ & No \\
\hline \multicolumn{7}{|l|}{ Phenotypic assays } \\
\hline Action potential ${ }^{\mathrm{e}}$ & APC & ESC-CM, iPSC-CM & 96,384 & $10 \mathrm{kHz}$ & PatchPlate ( \$400/plate) & No \\
\hline Field potential $(\mathrm{FP})^{\mathrm{f}}$ & MEA & ESC-CM, iPSC-CM & 12,48 & $50 \mathrm{kHz}$ & MEA plate $(\sim 500 /$ plate $)$ & Yes \\
\hline Impedance $^{\mathrm{g}}$ & RTCA & ESC-CM, iPSC-CM & 96 & $80 \mathrm{~Hz}$ & E-plate $(\sim 500 /$ plate $)$ & Yes \\
\hline $\mathrm{Ca}^{2+}$ dynamics ${ }^{\mathrm{h}}$ & FLIPR & iPSC-CM & $96,384,1536$ & $8 \mathrm{~Hz}$ & $\begin{array}{c}\text { Clear-bottom, black well } 96 \\
\text { or 384-plate ( } \$ 5 / \text { plate })\end{array}$ & No \\
\hline
\end{tabular}

a Cardiomyocytes-based, unless indicated otherwise (e.g., stably expressing lines using HEK or CHO cells)

b Bulk ordering may reduce the running cost of different systems. Abbreviations as defined in the text

c Notes: Predicts LQT based on hERG channel inhibition with $78 \%$ accuracy. Less sensitive than APC (Bridal et al. 2010; Huang et al. 2010; Xia et al. 2011)

d Notes: Predicts LQT based on hERG channel inhibition with $73 \%$ accuracy (Beacham et al. 2010; Danker and Moller 2014; Jorgensen et al. 2013; Li et al. 2011; Ly et al. 2007; Wible et al. 2005; Zeng et al. 2008)

e Notes: Recorded in current-clamp mode. Altered APD from multiple mechanisms (Becker et al. 2013; Ma et al. 2011)

${ }^{f}$ Notes: Predicts LQT with $100 \%$ accuracy based on FPD prolongation; Noninvasive, medium throughput (Asakura et al. 2015; Clements and Thomas 2014; Fendyur and Spira 2012; Harris et al. 2013; Navarrete et al. 2013; Pradhapan et al. 2013)

g Notes: Predicts cardiotoxicity with $84 \%$ accuracy based on beating irregularities. Noninvasive, medium throughput (Doherty et al. 2015; Guo et al. 2011; Himmel 2013; Nguemo et al. 2012; Pan et al. 2015; Wang et al. 2013; Xi et al. 2011)

${ }^{\mathrm{h}}$ Notes: Predicts cardiotoxicity with $96 \%$ accuracy based on the alternation of $\mathrm{Ca}^{2+}$ dynamics. Dye loading may affect the electrophysiological properties of the cardiomyocytes (Sirenko et al. 2014) 
impressive advances since its introduction. So far, however, the hands of a skilled experimenter still give the conventional approach a decisive edge over automated patch clamping, which provides unparalleled sensitivity and data reliability. Yet, industrial as well as academic laboratories have recognized the value of automated patch clamping which drives the development over ever-more sophisticated, rapid-throughput systems that through the use of automated cell handling and drug dispensing can now generate up to 10,000 data points per day (Dunlop et al. 2008; Elkins et al. 2013; Farre and Fertig 2014; Farre et al. 2009; Stoelzle et al. 2011). Essential for the successful deployment of these machines is their ability to establish good cell-electrode contact, because ionic current behave much like water: It will find the path of lowest resistance. Consequently, if the connection between the pipette mouth and the cell is loose, the measured signal will be a mixture of current going through the cell's ion channels and current escaping between the pipette mouth and the cell membrane ("leak current"). Since ion channels commonly provide comparatively high-resistance pathways, leak current can make up the majority of the measured signal. The goal is, therefore, to provide the best possible seal between the pipette mouth and the cell membrane. To afford highquality measurements, the resistance of this seal normally lies at or above 1 gigaohm $(\mathrm{G} \Omega)$, which explains the origin of all-decisive "gigaseal" in electrophysiology. In conventional patch clamping, gigaseals are the result of careful pipette fabrication, highly trained micromanipulation, pressure changes, and voltage adjustments. In automated patch clamping, the borosilicate pipette electrode has been replaced by a planar electrode arrangement where dissociated cells are dispensed into a small chamber with a single hole at the bottom. The hole is the equivalent of the pipette's mouth; it can be occluded by a cell covering it. The system then sucks the cell into a high-resistance position to rupture its cell membrane at the hole interface, effectively establishing a bottom-up connection to the cell. The chamber is, hence, the extracellular side (comparable to the bath in conventional patch clamping), while the circuitry under the chamber's hole is the intracellular side (i.e., the "pipette" with attached amplifier in conventional patch clamp terms). Providing high-quality gigaseals with planar electrodes employs diverse approaches which have been reviewed in elsewhere (Dunlop et al. 2008; Farre and Fertig 2012; Farre et al. 2007).

Automated patch clamping has been used to establish the potencies of a variety of ion channel ligands using heterologously expressed ion channels in mammalian cells. These ion channels include voltage-gated $\mathrm{K}^{+}$channels, such as hERG (Huang et al. 2010; Stoelzle et al. 2011; Tang et al. 2001), hKCNQ1/minK (Cao et al. 2010), voltage-gated $\mathrm{Na}^{+}$channels (Cao et al. 2010; Castle et al.
2009; Stoelzle et al. 2011), and voltage-gated $\mathrm{Ca}^{2+}$ channels (Cao et al. 2010). In many, but not all cases, the concentration-dependent inhibition values matched what had been established by conventional patch clamping. For some hKCNQ1/minK channel blockers, however, the suggested potencies were 25-40 times lower than indicated by the $\mathrm{IC}_{50}$ values from conventional patch clamping data, demonstrating that automated patch clamping can have its fallacies (Cao et al. 2010). Commonly, failure of automated patch clamping is related to the biophysical requirements of the experiment. The conventional approach has a skilled experimenter who can intervene if the recording conditions change. Automated patch clamping accomplishes this only with difficulty. In many cases, certain parameters are measured at the beginning and assumed to be constant throughout the experiment. This, however, is rarely the case. The seal may deteriorate (thus elevating the leak current component), or the cell may reseal and decrease the diameter of the hole connecting the amplifier with the cell's interior. The latter defines the so-called access resistance $\left(R_{\mathrm{a}}\right)$, which is a functional bottleneck that limits the system's ability to mediate rapid and potentially large current flow during voltage steps. For channels with fast gating kinetics, low $R_{\mathrm{a}}$ is vital to enable a rapid clamp to a new potential. This is especially true for $\mathrm{Na}_{\mathrm{v}}$ channels whose gating kinetics terminate within $3 \mathrm{~ms}$, making fast clamping speed, and, by extension, very low $R_{\mathrm{a}}$, a prerequisite for good voltage control. Successful measurements of $\mathrm{Na}_{\mathrm{v}}$ currents are technically most demanding, but various $\mathrm{Na}_{\mathrm{v}}$ channels $\left(\mathrm{Na}_{\mathrm{v}} 1.3\right.$, $\mathrm{Na}_{\mathrm{v}} 1.5, \mathrm{Na}_{\mathrm{v}} 1.7$, etc.) have been clamped and pharmacologically screened using automated patch clamping systems. The data suggest that the biophysical parameters (i.e., IV relationship, steady-state inactivation, etc.) as well as the $\mathrm{IC}_{50}$ values seem to be consistent with what has been seen with conventional measurements (Cao et al. 2010; Castle et al. 2009). Moreover, automated patch clamp technology advances rapidly, now even accommodating measurements on use-dependent sodium channel blockade (e.g., tetracaine on $\mathrm{Na}_{\mathrm{v}}$ 1.5), which suggests that current experimental limitations may be overcome soon, providing a highly sensitive, rapid-throughput screening platform for cardiotoxicity studies (Stoelzle et al. 2011).

Of course, cardiotoxicity predictions based on automated patch clamp data can also be misleading, owing to the analytical environment. Heterologous expression experiments, with their approach of reflecting drug actions on an isolated protein, carry the potential that natural, more complex drug relationships are missed. For example, a drug could bind to multiple targets, which may potentiate or mitigate the predicted arrhythmia (Moller 2010; Witchel et al. 2003a, b). Verapamil, for instance, is a potent hERG channel blocker, but it is not torsadogenic because of its concomitant action on L-type $\mathrm{Ca}^{2+}$ channels (Lacerda et al. 
2008; Navarrete et al. 2013). In these cases, reliance on heterologous automated patch clamp data would unnecessarily exclude an otherwise promising drug candidate. Compared to FLIPR-based hERG channel screening, which predicts long-QT syndrome propensity with $77.7 \%$ accuracy, automated patch clamping does not necessarily perform better (Beattie et al. 2013). It should also be kept in mind that, while systems show an almost exponential increase in the well format $(8,16,64,384$ wells), the success rate approximates $60-80 \%$ for highly trained personnel; for users with less experience, success of $<50 \%$ is not uncommon. In most cases, failure is attributed cell quality, where "quality" is determined by cell membrane properties, dissociation, and the percentage of cells expressing the desired channel (Guthrie et al. 2005). In addition, the running cost for automated patch clamping is commonly high due to sophisticated plates, such that any one experiment may cost hundreds of dollars. This, however, may be more than off-set by the versatility of automated patch clamping: Aside from measuring heterologously generated currents (Bruggemann et al. 2006; Farre et al. 2007, 2009), these systems can also record from cell with endogenous currents, for example cardiomyocytes derived from embryonic stem cells (ESC) or induced pluripotent stem cells (iPSC) (Becker et al. 2013; Ma et al. 2011). This has the decisive advantage that the entire complement of cardiac cofactors and channels are present. Furthermore, cardiomyocytes derived from iPSCs or ESCs express cardiac-specific genes and proteins, allowing them to assume atrial, nodal, and ventricular cardiac action potential behavior within the physiological range (Haythornthwaite et al. 2012; Ma et al. 2011). Automated patch clamping with such setups, especially in the current-clamp mode, can be highly predictive of a drug's potential to affect cardiac excitation. Veratridine, for example, has been examined in this fashion, and its sodium channel activation has been shown to prolong the action potential duration (Chevalier et al. 2014). Nifedipine and lidocaine, examined under current clamp, similarly have been found to modulate various parameters, including the cardiac action potential amplitude/duration (Stoelzle et al. 2011).

Stem cell-derived cardiomyocytes nicely reproduce human physiological conditions, but data produced with these systems still requires validation with large sets of positive and negative reference compounds, because the correlation with adult cardiac physiology, and, by extension, its pharmacological sensitivity is, at this time, not very well understood. The problem is that iPSC- and ESC-derived cardiomyocytes are likely in a neonatal state, making the type and/or expression level of ion channels uniquely distinct from that of adult cells (Binah et al. 2007; $\mathrm{Xi}$ et al. 2011). Also, consideration must be taken that automated patch clamping requires cellular dissociation, which disrupts intercellular networks. It is unclear at this point, if human ESC-/iPSC-derived cardiomyocytes altered their ionic currents with the loss of network connections in suspension (Kujala et al. 2012; Lahti et al. 2012).

\section{Microelectrode array field potential measurements}

The microelectrode array (MEA) is a medium-throughput assay designed to measure field potentials from electrically active cellular networks. It has been used on different types of cardiomyocytes, primary, as well as those derived from ESCs, and iPSCs, to predict QT prolongation and torsadogenicity (Fendyur and Spira 2012; Guo et al. 2011; Harris et al. 2013). The field potential duration (FPD) has been shown to correlate with action potential duration when both are recorded simultaneously (Fendyur and Spira 2012; Halbach et al. 2003). More importantly, QT correlation appears to be in place as well, as established by in vivo ECG data (Guo et al. 2011; Harris et al. 2013). An MEA system combines a cell culture plate with an embedded array of highimpedance or low-impedance electrodes, an amplifier, a digitizer sampling at $>50 \mathrm{kHz}$, and associated analysis software (Meyer et al. 2004; Scheel et al. 2014). Using this setup, FDP modulation of ESC-derived cardiomyocytes has been examined under exposure to different reference compounds (Braam and Mummery 2010). Lidocaine, a sodium channel blocker, terminated spikes in the $30-100 \mu \mathrm{M}$ concentration range, which is consistent with published $\mathrm{IC}_{50}$ values. Nifedipine, a $\mathrm{Ca}^{2+}$ channel blocker, shortened FPD, but increased spike frequency, albeit with no arrhythmic behavior. The hERG channel blocker E-4031 induced sustained FDP prolongation at $30 \mathrm{nM}$ (Braam and Mummery 2010; Navarrete et al. 2013). Most informative were the effects of nine compounds with established torsadogenicity and QT prolongation (alfuzosin, cisapride, sparfloxacin, terfenadine, domperidone, sertindole, quinidine, sotalol, and amiodarone). Three independent studies confirmed their FDP prolonging characteristic; no false negatives were observed (Braam and Mummery 2010; Meyer et al. 2004). Interestingly, FPD prolongation appears to have superior cardiac event prediction value, since hESC-derived cardiomyocytes flag no adverse drug effects with verapamil and ketoconazole, which have been demonstrated to be hERG channel inhibitors (Braam and Mummery 2010; Redfern et al. 2003). These findings suggest that electrophysiological properties and drug responses of human ESC-derived cardiomyocytes match clinical observations on QT prolongation/shortening and arrhythmogenicity. More importantly, when the drug profiling is extended from the single parametric FDP approach to consider multiple field potential characteristics (e.g., spike amplitude, spike frequency, etc.), the assay's sensitivity for cardiac risk is further enhanced (Clements and Thomas 2014). 
The great advantage of the MEA platform is that it affords the opportunity to conduct experiments with intact cellular networks. Also, because the cells are continuously cultured and maintained, it is possible to conduct true time response measurements, which provide insight into subacute drug responses. Of course, due to its tissue complexity, the method is relatively low throughput, currently topping out at the 48-well format, although 96-well systems are available (Scheel et al. 2014). Another drawback is the comparatively high cost of the MEA plates $(\sim 500$ / plate), although wider adoption of this technology may soon make these types of platforms more economical. It should be emphasized that MEA recordings produce enormous amounts of data that can obscure the important from the irrelevant. This, however, is not different from many other modern research technologies (e.g., next-generation sequencing), and it can be assumed that the analysis burden will soon become more manageable. First, semiautomatic data analysis tools have already become available (Pradhapan et al. 2013). Even with this analysis obstacle still in place, MEA allows for high-resolution, noninvasive electrophysiological recordings on cardiomyocytes with a high correlation between FDP prolongation and clinical longQT syndrome, which makes it a remarkably powerful cardiotoxicity prediction tool (Braam and Mummery 2010).

\section{Real-time cell analysis}

Real-time cell analysis (RTCA) is a proprietary, impedance-based technology that can monitor the cardiomyocyte contraction-relaxation cycle at millisecond resolution in 96-well format without the need for labeling (Xi et al. 2011). A variety of reference cardiac modulators have been tested using RTCA, in an effort to determine their influence on cardiomyocyte contractility (Xi et al. 2011). In setups using murine ESCs, tetrodotoxin, a sodium channel blocker, decreased the beating rate, whereas isradipine, a voltage-gated $\mathrm{Ca}^{2+}$ channel inhibitor, decreased spike amplitude and frequency; similar analyses showed that (S)-(-)Bay K 8644 depressed the beating rate (Abassi et al. 2012; Xi et al. 2011). Four drugs withdrawn from the market due to increased torsade incidence, astemizole, cisapride, droperide, and sertindole, all produced beating irregularities consistent with those observed for the hERG blocker E4031. However, another hERG channel blocker, terfenadine, failed to produce any effect (Abassi et al. 2012). These data suggest that different mechanisms are in place when it comes to disrupting the mechanical activity of cardiomyocytes, and multiple beating parameters such as rate, intensity, and duration can be used to assess contraction abnormalities (Himmel 2013). One study examining the effects of 49 positive and negative inotropes as well as non-actives using human iPSC-derived cardiomyocytes showed that non-active controls were identified as such with $74 \%$ prediction reliability. Seven out of nine positive inotropes were correctly identified as active (78\% reliability), while 20 out of 21 negative inotropes produced the expected outcome, indicating $95 \%$ reliability (Scott et al. 2014). This shows that RTCA-based assaying has fairly good prediction value based on European Centre for the Validation of Alternative Methods criteria (Genschow et al. 2002).

Like MEA, RTCA is noninvasive, permitting recordings from cultures following subacute compound exposure (Pan et al. 2013). This is of particular relevance for molecules binding to non-ion channel targets, whose effects may take longer to manifest, making it impossible to capture them with assays emphasizing hERG activity or action potential parameters (Himmel 2013). The chemotherapeutic agent doxorubicin, for example, has been shown to induce arrhythmia as well as cardiotoxicity by interfering with mitochondrial function. It was RTCA that enabled the detection of the delayed decrease in the cardiomyocyte beating frequency (Abassi et al. 2012). Despite these promising results, the predictive or even translational value of RTCA is considered limited, because its validity is not yet firmly established (Himmel 2013). Also challenging is the cost of the RTCA consumables, in particular for the plates, which makes RTCA medium throughput. Nevertheless, this technology, coupled with stem cell-derived cardiomyocytes, has the potential for primary, secondary, and safety pharmacology (Harding et al. 2007; Mandenius et al. 2011; Pouton and Haynes 2007).

\section{Measurement of intracellular $\mathrm{Ca}^{2+}$ dynamics}

The mechanical beating process of a syncytial bed of cardiomyocytes is highly synchronous, and throughout the cardiac cycle, it correlates with the dynamic changes in intracellular $\mathrm{Ca}^{2+}$ (Sirenko et al. 2014). Visualization of intracellular $\mathrm{Ca}^{2+}$ dynamics, therefore, provides insight into cardiomyocyte mechanics (Sirenko et al. 2014). The FLIPR platform, initially developed to monitor $\mathrm{Ca}^{2+}$ changes associated with G-protein coupled receptor activation (Niedernberg et al. 2003), has been repurposed toward primary cultured neuronal networks (Cao et al. 2012, 2014) and cardiomyocytes, where it can provide real-time (8 Hz) fluorescence data for 96-, 384-, and even 1536-well plates (Sirenko et al. 2014). With a throughput of 50,000 data points per day (Dorn et al. 2005), FLIPR-based $\mathrm{Ca}^{2+}$ imaging is highly efficient, which has prompted the development of follow-up, improved technology. Various positive and negative reference compounds targeting distinct ion channels have been tested with the FLIPR platform, which confirmed this method's capability of capturing the cardiomyocytes $\mathrm{Ca}^{2+}$ oscillations to make measurements 
on fluorescence peak width, peak spacing, peak rise, and peak decay times. When tested with hERG channel inhibitors cisapride, terfenadine, astemizole, and pimozide, all compounds characteristically delayed $\mathrm{Ca}^{2+}$ baseline recovery (Sirenko et al. 2014). Sodium channel blockers lidocaine and tetrodotoxin produced slowed beating frequency and various other irregularities in a concentrationdependent fashion with potencies similar to what has been established for their actions on sodium channels (Sirenko et al. 2014). Drugs with positive chronotropic effects can be readily identified, and various ion channel modulators induce the expected inhibition of contractile activity (Sirenko et al. 2014). The FLIPR system is also suitable for capturing subacute responses in $\mathrm{Ca}^{2+}$ dynamics following compound exposure, as demonstrated by delayed cardiotoxic effects $24 \mathrm{~h}$ after administration of pentamidine and quinidine (Sirenko et al. 2014). These findings are encouraging, but whether or not the measured $\mathrm{Ca}^{2+}$ dynamics can sufficiently parallel critical clinical events such as long-QT syndrome or torsade remains to be established. There is, however, good concordance with clinical data for known chronotropes and/or inotropes. Coupled with an immensely high-throughput capability and comparatively low cost, FLIPR $\mathrm{Ca}^{2+}$ imaging will likely find widespread utility for preclinical cardiotoxicity testing. It is also experimentally convenient, requiring only standard black well, clear-bottom 96- or 386-well plate, which is much more economical than the high-tech plates required for MEA and RTCA analyses. Of course, at $8 \mathrm{~Hz}$, the temporal resolution of FLIPR is relative low, which limits its detail on $\mathrm{Ca}^{2+}$ dynamics, especially when the beating rate is stimulated (Cao et al. 2015). As in other systems where indicators must be loaded, caution is necessary when it comes to interpreting the data, as the presence of the labeling chemicals may affect the electrophysiological properties of the cells (Fendyur and Spira 2012; Peters et al. 2015).

\section{Conclusion}

Cardiotoxicity is one of the leading causes for discontinuation at different phases of drug development. Various screening technologies seek to predict the same based on hERG activity, yet inhibition of hERG current alone cannot possibly encompass the diverse set of mechanisms behind drug-induced cardiac arrhythmias. Promising in this regard are phenotypic measurements of more native cellular systems examining action potential or field potential duration, contractility, and $\mathrm{Ca}^{2+}$ dynamics in human ESCand iPSC-derived cardiomyocytes. These assays, however, are comparatively time-consuming, which is in conflict with screening economy, suggesting that simpler and more convenient approaches such a FLIPR-based hERG $\mathrm{Tl}^{+}$ influx and $\mathrm{Ca}^{2+}$ dye technology ought to be used in the earliest stages. Compounds displaying a safe profile in the latter two assays could then be subjected to MEA testing, while automated patch clamping ought to be employed to study associated mechanisms of action.

Acknowledgments This research was supported by the Natural Science Foundation of China [Grant 81473539, 21525730, 21177150], the Jiangsu Provincial Natural Science Foundation [Grant BK20141357], Strategic Priority Research Program of the Chinese Academy of Sciences [Grant XDB14030401] and the Project Program of State Key Laboratory of Natural Medicines, China Pharmaceutical University [Grant SKLNMZZJQ201402].

\section{Compliance with ethical standards}

Conflict of interest The authors declare that they have no conflict of interest.

\section{References}

Abassi YA, Xi B, Li N et al (2012) Dynamic monitoring of beating periodicity of stem cell-derived cardiomyocytes as a predictive tool for preclinical safety assessment. $\mathrm{Br} \mathrm{J}$ Pharmacol 165(5):1424-1441

Abe AM, Hein DJ, Gregory PJ (2015) Regulatory alerts for dietary supplements in Canada and the United States, 2005-13. Am J Health Syst Pharm 72(11):966-971

Abriel H, Rougier JS, Jalife J (2015) Ion channel macromolecular complexes in cardiomyocytes: roles in sudden cardiac death. Circ Res 116(12):1971-1988

Agarwal AK, Ram J, Singh R (2014) Sparfloxacin-associated corneal epithelial toxicity. BMJ Case Rep. doi:10.1136/ bcr-2014-203786

Apostolakis S, Oeff M, Tebbe U, Fabritz L, Breithardt G, Kirchhof P (2013) Flecainide acetate for the treatment of atrial and ventricular arrhythmias. Expert Opin Pharmacother 14(3):347-357

Asakura K, Hayashi S, Ojima A et al (2015) Improvement of acquisition and analysis methods in multi-electrode array experiments with iPS cell-derived cardiomyocytes. J Pharmacol Toxicol Methods 75:17-26

Baudenbacher F, Schober T, Pinto JR et al (2008) Myofilament Ca2 ${ }^{+}$ sensitization causes susceptibility to cardiac arrhythmia in mice. J Clin Investig 118(12):3893-3903

Beacham DW, Blackmer T, O'Grady M, Hanson GT (2010) Cellbased potassium ion channel screening using the FluxOR assay. J Biomol Screen 15(4):441-446

Beattie KA, Luscombe C, Williams G et al (2013) Evaluation of an in silico cardiac safety assay: using ion channel screening data to predict QT interval changes in the rabbit ventricular wedge. $\mathrm{J}$ Pharmacol Toxicol Methods 68(1):88-96

Becker N, Stoelzle S, Gopel S et al (2013) Minimized cell usage for stem cell-derived and primary cells on an automated patch clamp system. J Pharmacol Toxicol Methods 68(1):82-87

Becquemont L, Delespierre T, Bauduceau B et al (2014) Consequences of dextropropoxyphene market withdrawal in elderly patients with chronic pain. Eur J Clin Pharmacol 70(10): 1237-1242

Bellocq C, Wilders R, Schott JJ et al (2004) A common antitussive drug, clobutinol, precipitates the long QT syndrome 2. Mol Pharmacol 66(5):1093-1102 
Benay S, Meille C, Kustermann S et al (2015) Model-based assessment of erlotinib effect in vitro measured by real-time cell analysis. J Pharmacokinet Pharmacodyn 42(3):275-285

Bento AP, Gaulton A, Hersey A et al (2014) The ChEMBL bioactivity database: an update. Nucleic Acids Res 42(Database issue):D1083-D1090

Bezprozvanny I, Tsien RW (1995) Voltage-dependent blockade of diverse types of voltage-gated $\mathrm{Ca}^{+}$channels expressed in Xenopus oocytes by the $\mathrm{Ca} 2^{+}$channel antagonist mibefradil (Ro 40-5967). Mol Pharmacol 48(3):540-549

Binah O, Dolnikov K, Sadan O et al (2007) Functional and developmental properties of human embryonic stem cells-derived cardiomyocytes. J Electrocardiol 40(6 Suppl):S192-S196

Blayney LM, Lai FA (2009) Ryanodine receptor-mediated arrhythmias and sudden cardiac death. Pharmacol Ther 123(2):151-177

Boverhof DR, Zacharewski TR (2006) Toxicogenomics in risk assessment: applications and needs. Toxicol Sci 89(2):352-360

Braam SR, Mummery CL (2010) Human stem cell models for predictive cardiac safety pharmacology. Stem Cell Res 4(3):155-156

Brana I, Tabernero J (2010) Cardiotoxicity. Ann Oncol 21(Suppl 7):vii173-vii179

Bridal TR, Margulis M, Wang X, Donio M, Sorota S (2010) Comparison of human Ether-a-go-go related gene screening assays based on IonWorks Quattro and thallium flux. Assay Drug Dev Technol 8(6):755-765

Bridgland-Taylor MH, Hargreaves AC, Easter A et al (2006) Optimisation and validation of a medium-throughput electrophysiology-based hERG assay using IonWorks HT. J Pharmacol Toxicol Methods 54(2):189-199

Bruggemann A, Stoelzle S, George M, Behrends JC, Fertig N (2006) Microchip technology for automated and parallel patch-clamp recording. Small 2(7):840-846

Burashnikov A, Antzelevitch C (2003) Reinduction of atrial fibrillation immediately after termination of the arrhythmia is mediated by late phase 3 early afterdepolarization-induced triggered activity. Circulation 107(18):2355-2360

Butola S, Rajagopal M (2015) Ban on dextropropoxyphene is unjustifiable. Indian J Palliat Care 21(1):3-7

Cao X, Lee YT, Holmqvist M et al (2010) Cardiac ion channel safety profiling on the IonWorks Quattro automated patch clamp system. Assay Drug Dev Technol 8(6):766-780

Cao Z, Hammock BD, McCoy M, Rogawski MA, Lein PJ, Pessah IN (2012) Tetramethylenedisulfotetramine alters $\mathrm{Ca}^{+}$dynamics in cultured hippocampal neurons: mitigation by NMDA receptor blockade and $\operatorname{GABA}(\mathrm{A})$ receptor-positive modulation. Toxicol Sci 130(2):362-372

Cao Z, Cui Y, Busse E, Mehrotra S, Rainier JD, Murray TF (2014) Gambierol inhibition of voltage-gated potassium channels augments spontaneous $\mathrm{Ca}^{+}{ }^{+}$oscillations in cerebrocortical neurons. J Pharmacol Exp Ther 350(3):615-623

Cao Z, Zou X, Cui Y et al (2015) Rapid throughput analysis demonstrates that chemicals with distinct seizurogenic mechanisms differentially alter $\mathrm{Ca}_{2}{ }^{+}$dynamics in networks formed by hippocampal neurons in culture. Mol Pharmacol 87(4):595-605

Cardinale D, Bacchiani G, Beggiato M, Colombo A, Cipolla CM (2013) Strategies to prevent and treat cardiovascular risk in cancer patients. Semin Oncol 40(2):186-198

Castle N, Printzenhoff D, Zellmer S, Antonio B, Wickenden A, Silvia C (2009) Sodium channel inhibitor drug discovery using automated high throughput electrophysiology platforms. Comb Chem High Throughput Screen 12(1):107-122

Chen J, Seebohm G, Sanguinetti MC (2002) Position of aromatic residues in the S6 domain, not inactivation, dictates cisapride sensitivity of HERG and eag potassium channels. Proc Natl Acad Sci USA 99(19):12461-12466
Chen X, Yang L, Zhai SD (2012) Risk of cardiovascular disease and all-cause mortality among diabetic patients prescribed rosiglitazone or pioglitazone: a meta-analysis of retrospective cohort studies. Chin Med J 125(23):4301-4306

Cheng YP, Ma T, He RR (2003) Electrophysiological effects of phytoestrogen genistein on spontaneous activity of rabbit atrioventricular node cells. Sheng Li Xue Bao 55(1):9-13

Cheng F, Li W, Zhou Y et al (2012) admetSAR: a comprehensive source and free tool for assessment of chemical ADMET properties. J Chem Inf Model 52(11):3099-3105

Chevalier M, Amuzescu B, Gawali V et al (2014) Late cardiac sodium current can be assessed using automated patch-clamp. F1000Res 3, p 245

Clements M, Thomas N (2014) High-throughput multi-parameter profiling of electrophysiological drug effects in human embryonic stem cell derived cardiomyocytes using multi-electrode arrays. Toxicol Sci 140(2):445-461

Curran ME, Splawski I, Timothy KW, Vincent GM, Green ED, Keating MT (1995) A molecular basis for cardiac arrhythmia: HERG mutations cause long QT syndrome. Cell 80(5):795-803

Danker T, Moller C (2014) Early identification of hERG liability in drug discovery programs by automated patch clamp. Front Pharmacol 5:203

Dennis AT, Wang L, Wan H, Nassal D, Deschenes I, Ficker E (2012) Molecular determinants of pentamidine-induced hERG trafficking inhibition. Mol Pharmacol 81(2):198-209

Ding M, Stjernborg L, Albertson N (2006) Application of cryopreserved cells to HERG screening using a non-radioactive $\mathrm{Rb}^{+}$ efflux assay. Assay Drug Dev Technol 4(1):83-88

Doddareddy MR, Klaasse EC, Shagufta Ijzerman AP, Bender A (2010) Prospective validation of a comprehensive in silico hERG model and its applications to commercial compound and drug databases. ChemMedChem 5(5):716-729

Doherty KR, Talbert DR, Trusk PB, Moran DM, Shell SA, Bacus S (2015) Structural and functional screening in human inducedpluripotent stem cell-derived cardiomyocytes accurately identifies cardiotoxicity of multiple drug types. Toxicol Appl Pharmacol 285(1):51-60

Dorn A, Hermann F, Ebneth A et al (2005) Evaluation of a highthroughput fluorescence assay method for HERG potassium channel inhibition. J Biomol Screen 10(4):339-347

Du F, Yu H, Zou B, Babcock J, Long S, Li M (2011) hERGCentral: a large database to store, retrieve, and analyze compound-human Ether-a-go-go related gene channel interactions to facilitate cardiotoxicity assessment in drug development. Assay Drug Dev Technol 9(6):580-588

Dunlop J, Bowlby M, Peri R, Vasilyev D, Arias R (2008) Highthroughput electrophysiology: an emerging paradigm for ion-channel screening and physiology. Nat Rev Drug Discov 7(4):358-368

Durdagi S, Randall T, Duff HJ, Chamberlin A, Noskov SY (2014) Rehabilitating drug-induced long-QT promoters: in silico design of hERG-neutral cisapride analogues with retained pharmacological activity. BMC Pharmacol Toxicol 15:14

Echt DS, Liebson PR, Mitchell LB et al (1991) Mortality and morbidity in patients receiving encainide, flecainide, or placebo. The Cardiac Arrhythmia Suppression Trial. N Engl J Med 324(12):781-788

Elkins RC, Davies MR, Brough SJ et al (2013) Variability in highthroughput ion-channel screening data and consequences for cardiac safety assessment. J Pharmacol Toxicol Methods 68(1):112-122

Farre C, Fertig N (2012) HTS techniques for patch clamp-based ion channel screening —advances and economy. Expert Opin Drug Discov 7(6):515-524 
Farre C, Fertig N (2014) New strategies in ion channel screening for drug discovery: are there ways to improve its productivity? Expert Opin Drug Discov 9(10):1103-1107

Farre C, Stoelzle S, Haarmann C, George M, Bruggemann A, Fertig N (2007) Automated ion channel screening: patch clamping made easy. Expert Opin Ther Targets 11(4):557-565

Farre C, Haythornthwaite A, Haarmann C et al (2009) Port-a-patch and patchliner: high fidelity electrophysiology for secondary screening and safety pharmacology. Comb Chem High Throughput Screen 12(1):24-37

Fendyur A, Spira ME (2012) Toward on-chip, in-cell recordings from cultured cardiomyocytes by arrays of gold mushroom-shaped microelectrodes. Front Neuroeng 5:21

Fenton M, Rathbone J, Reilly J, Sultana A (2007) Thioridazine for schizophrenia. Cochrane Database Syst Rev 18(3):CD001944

Fernandez D, Ghanta A, Kauffman GW, Sanguinetti MC (2004) Physicochemical features of the HERG channel drug binding site. $\mathrm{J}$ Biol Chem 279(11):10120-10127

Ficker E, Jarolimek W, Kiehn J, Baumann A, Brown AM (1998) Molecular determinants of dofetilide block of HERG $\mathrm{K}^{+}$channels. Circ Res 82(3):386-395

Filz O, Lagunin A, Filimonov D, Poroikov V (2008) Computeraided prediction of QT-prolongation. SAR QSAR Environ Res 19(1-2):81-90

Fornaro P, Calabria G, Corallo G, Picotti GB (2002) Pathogenesis of degenerative retinopathies induced by thioridazine and other antipsychotics: a dopamine hypothesis. Doc Ophthalmol 105(1):41-49

Frea S, Giustetto C, Capriolo M et al (2015) New echocardiographic insights in short QT syndrome: More than a channellopathy? Heart Rhythm 12(10):2096-2105

Genschow E, Spielmann H, Scholz G et al (2002) The ECVAM international validation study on in vitro embryotoxicity tests: results of the definitive phase and evaluation of prediction models. European Centre for the Validation of Alternative Methods. ATLA 30(2):151-176

Gfeller D, Grosdidier A, Wirth M, Daina A, Michielin O, Zoete V (2014) SwissTargetPrediction: a web server for target prediction of bioactive small molecules. Nucleic Acids Res 42(Web Server issue):W32-W38

Giacomini E, Buonfiglio R, Masetti M et al (2015) A ligand-based virtual screening approach to identify small molecules as HERG channel activators. Comb Chem High Throughput Screen 18(3):269-280

Giudicessi JR, Ackerman MJ (2013) Arrhythmia risk in long QT syndrome: beyond the disease-causative mutation. Circul Cardiovasc Genet 6(4):313-316

Guo L, Abrams RM, Babiarz JE et al (2011) Estimating the risk of drug-induced proarrhythmia using human induced pluripotent stem cell-derived cardiomyocytes. Toxicol Sci 123(1):281-289

Guthrie H, Livingston FS, Gubler U, Garippa R (2005) A place for high-throughput electrophysiology in cardiac safety: screening hERG cell lines and novel compounds with the ion works HTTM system. J Biomol Screen 10(8):832-840

Halbach M, Egert U, Hescheler J, Banach K (2003) Estimation of action potential changes from field potential recordings in multicellular mouse cardiac myocyte cultures. Cell Physiol Biochem 13(5):271-284

Hamill OP, Marty A, Neher E, Sakmann B, Sigworth FJ (1981) Improved patch-clamp techniques for high-resolution current recording from cells and cell-free membrane patches. Pflugers Arch 391(2):85-100

Hamilton KL, Harris AC, Gewirtz JC (2013) Affective and neuroendocrine effects of withdrawal from chronic, long-acting opiate administration. Brain Res 1538:73-82
Harding SE, Ali NN, Brito-Martins M, Gorelik J (2007) The human embryonic stem cell-derived cardiomyocyte as a pharmacological model. Pharmacol Ther 113(2):341-353

Harris K, Aylott M, Cui Y, Louttit JB, McMahon NC, Sridhar A (2013) Comparison of electrophysiological data from humaninduced pluripotent stem cell-derived cardiomyocytes to functional preclinical safety assays. Toxicol Sci 134(2):412-426

Hassan HA, El-Gharib NE (2015) Obesity and clinical riskiness relationship: therapeutic management by dietary antioxidant supplementation-a review. Appl Biochem Biotechnol 176(3):647-69

Hayes JF, Bhaskaran K, Batterham R, Smeeth L, Douglas I (2015) The effect of sibutramine prescribing in routine clinical practice on cardiovascular outcomes: a cohort study in the United Kingdom. Int J Obes (Lond) 39(9):1359-1364

Haythornthwaite A, Stoelzle S, Hasler A et al (2012) Characterizing human ion channels in induced pluripotent stem cell-derived neurons. J Biomol Screen 17(9):1264-1272

Himmel HM (2013) Drug-induced functional cardiotoxicity screening in stem cell-derived human and mouse cardiomyocytes: effects of reference compounds. J Pharmacol Toxicol Methods 68(1):97-111

Hondeghem LM, Dujardin K, Hoffmann P, Dumotier B, De Clerck F (2011) Drug-induced QTC prolongation dangerously underestimates proarrhythmic potential: lessons from terfenadine. J Cardiovasc Pharmacol 57(5):589-597

Huang XP, Mangano T, Hufeisen S, Setola V, Roth BL (2010) Identification of human Ether-a-go-go related gene modulators by three screening platforms in an academic drug-discovery setting. Assay Drug Dev Technol 8(6):727-742

Huang W, Lu C, Wu Y, Ouyang S, Chen Y (2015) T-type calcium channel antagonists, mibefradil and NNC-55-0396 inhibit cell proliferation and induce cell apoptosis in leukemia cell lines. J Exp Clin Cancer Res 34(1):54

Huikuri HV, Castellanos A, Myerburg RJ (2001) Sudden death due to cardiac arrhythmias. N Engl J Med 345(20):1473-1482

Huikuri HV, Raatikainen MJ, Moerch-Joergensen R et al (2009) Prediction of fatal or near-fatal cardiac arrhythmia events in patients with depressed left ventricular function after an acute myocardial infarction. Eur Heart J 30(6):689-698

Ishii K, Kondo K, Takahashi M, Kimura M, Endoh M (2001) An amino acid residue whose change by mutation affects drug binding to the HERG channel. FEBS Lett 506(3):191-195

Jorgensen S, Dyhring T, Brown DT, Strobaek D, Christophersen P, Demnitz J (2013) A high-throughput screening campaign for detection of $\mathrm{Ca}\left(2^{+}\right)$-activated $\mathrm{K}\left({ }^{+}\right)$channel activators and inhibitors using a fluorometric imaging plate reader-based $\left.\mathrm{Tl}^{+}\right)$influx assay. Assay Drug Dev Technol 11(3):163-172

Kamiya K, Mitcheson JS, Yasui K, Kodama I, Sanguinetti MC (2001) Open channel block of HERG $\left.\mathrm{K}^{+}\right)$channels by vesnarinone. Mol Pharmacol 60(2):244-253

Karamatskos E, Lambert M, Mulert C, Naber D (2012) Drug safety and efficacy evaluation of sertindole for schizophrenia. Expert Opin Drug Saf 11(6):1047-1062

Keating MT, Sanguinetti MC (2001) Molecular and cellular mechanisms of cardiac arrhythmias. Cell 104(4):569-580

Keiser MJ, Roth BL, Armbruster BN, Ernsberger P, Irwin JJ, Shoichet BK (2007) Relating protein pharmacology by ligand chemistry. Nat Biotechnol 25(2):197-206

Keks N, McGrath J, Lambert T et al (1994) The Australian multicentre double-blind comparative study of remoxipride and thioridazine in schizophrenia. Acta Psychiatr Scand 90(5):358-365

Khorassani FE, Misher A, Garris S (2015) Past and present of antiobesity agents: focus on monoamine modulators. Am J Health Syst Pharm 72(9):697-706 
Kim Kjaerulff S, Wich L, Kringelum J et al (2013) ChemProt-20: visual navigation in a disease chemical biology database. Nucleic Acids Res 41(Database issue):D464-D469

Kola I, Landis J (2004) Can the pharmaceutical industry reduce attrition rates? Nat Rev Drug Discov 3(8):711-715

Kujala K, Paavola J, Lahti A et al (2012) Cell model of catecholaminergic polymorphic ventricular tachycardia reveals early and delayed afterdepolarizations. PLoS One 7(9):e44660

Kurtzwald-Josefson E, Hochhauser E, Bogachenko K et al (2014) Alpha blockade potentiates CPVT therapy in calsequestrinmutant mice. Heart Rhythm 11(8):1471-1479

Lacerda AE, Kuryshev YA, Chen Y et al (2008) Alfuzosin delays cardiac repolarization by a novel mechanism. J Pharmacol Exp Ther 324(2):427-433

Lahti AL, Kujala VJ, Chapman H et al (2012) Model for long QT syndrome type 2 using human iPS cells demonstrates arrhythmogenic characteristics in cell culture. Dis Models Mech 5(2):220-230

Lees-Miller JP, Duan Y, Teng GQ, Duff HJ (2000) Molecular determinant of high-affinity dofetilide binding to HERG1 expressed in Xenopus oocytes: involvement of S6 sites. Mol Pharmacol 57(2):367-374

Li Q, Rottlander M, Xu M et al (2011) Identification of novel KCNQ4 openers by a high-throughput fluorescence-based thallium flux assay. Anal Biochem 418(1):66-72

Liu QN, Trudeau MC (2015) Eag domains regulate LQT mutant hERG channels in human induced pluripotent stem cell-derived cardiomyocytes. PLoS One 10(4):e0123951

Liu X, Vogt I, Haque T, Campillos M (2013) HitPick: a web server for hit identification and target prediction of chemical screenings. Bioinformatics 29(15):1910-1912

London B, Michalec M, Mehdi H et al (2007) Mutation in glycerol3-phosphate dehydrogenase 1 like gene (GPD1-L) decreases cardiac $\mathrm{Na}^{+}$current and causes inherited arrhythmias. Circulation 116(20):2260-2268

Lu HR, Vlaminckx E, Hermans AN et al (2008) Predicting druginduced changes in QT interval and arrhythmias: QT-shortening drugs point to gaps in the ICHS7B guidelines. Br J Pharmacol 154(7):1427-1438

Ly JQ, Shyy G, Misner DL (2007) Assessing hERG channel inhibition using PatchXpress. Clin Lab Med 27(1):201-208

Ma J, Guo L, Fiene SJ et al (2011) High purity human-induced pluripotent stem cell-derived cardiomyocytes: electrophysiological properties of action potentials and ionic currents. Am J Physiol Heart Circ Physiol 301(5):H2006-H2017

MacDonald JS, Robertson RT (2009) Toxicity testing in the 21st century: a view from the pharmaceutical industry. Toxicol Sci 110(1):40-46

Maeno Y, Hirose A, Kanbe T, Hori D (2009) Fetal arrhythmia: prenatal diagnosis and perinatal management. J Obstet Gynaecol Res 35(4):623-629

Mandenius CF, Steel D, Noor F et al (2011) Cardiotoxicity testing using pluripotent stem cell-derived human cardiomyocytes and state-of-the-art bioanalytics: a review. J Appl Toxicol 31(3):191-205

McNair WP, Ku L, Taylor MR et al (2004) SCN5A mutation associated with dilated cardiomyopathy, conduction disorder, and arrhythmia. Circulation 110(15):2163-2167

Medeiros-Domingo A, Kaku T, Tester DJ et al (2007) SCN4Bencoded sodium channel beta4 subunit in congenital long-QT syndrome. Circulation 116(2):134-142

Meyer T, Boven KH, Gunther E, Fejtl M (2004) Micro-electrode arrays in cardiac safety pharmacology: a novel tool to study QT interval prolongation. Drug Saf 27(11):763-772

Miller D, Wang L, Zhong J (2014) Chapter twelve-sodium channels, cardiac arrhythmia, and therapeutic strategy. In: Ya-Xiong T (ed) Advances in pharmacology, vol 70. Academic Press, London p, pp 367-392

Mitcheson JS (2003) Drug binding to HERG channels: evidence for a 'non-aromatic' binding site for fluvoxamine. Br J Pharmacol 139(5):883-884

Mitcheson JS, Chen J, Lin M, Culberson C, Sanguinetti MC (2000) A structural basis for drug-induced long QT syndrome. Proc Natl Acad Sci U S A 97(22):12329-12333

Moller C (2010) Keeping the rhythm: hERG and beyond in cardiovascular safety pharmacology. Expert Rev Clin Pharmacol 3(3):321-329

Moric-Janiszewska E, Herbert E, Cholewa K, Filipecki A, TruszGluza M, Wilczok T (2004) Mutational screening of SCN5A linked disorders in Polish patients and their family members. J Appl Genet 45(3):383-390

Nabel EG (2003) Cardiovascular disease. N Engl J Med 349(1):60-72

Navarrete EG, Liang P, Lan F et al (2013) Screening drug-induced arrhythmia [corrected] using human induced pluripotent stem cell-derived cardiomyocytes and low-impedance microelectrode arrays. Circulation 128(11 Suppl 1):S3-S13

Nguemo F, Saric T, Pfannkuche K, Watzele M, Reppel M, Hescheler J (2012) In vitro model for assessing arrhythmogenic properties of drugs based on high-resolution impedance measurements. Cell Physiol Biochem 29(5-6):819-832

Nickel J, Gohlke BO, Erehman J et al (2014) SuperPred: update on drug classification and target prediction. Nucleic Acids Res 42(Web Server issue):W26-W31

Niedernberg A, Tunaru S, Blaukat A, Ardati A, Kostenis E (2003) Sphingosine 1-phosphate and dioleoylphosphatidic acid are low affinity agonists for the orphan receptor GPR63. Cell Signal 15(4):435-446

Nissen SE, Wolski K (2007) Effect of rosiglitazone on the risk of myocardial infarction and death from cardiovascular causes. N Engl J Med 356(24):2457-2471

Numann R, Negulescu PA (2001) High-throughput screening strategies for cardiac ion channels. Trends Cardiovasc Med 11(2):54-59

Pan T, Khare S, Ackah F et al (2013) In vitro cytotoxicity assessment based on $\mathrm{KC}(50)$ with real-time cell analyzer (RTCA) assay. Comput Biol Chem 47:113-120

Pan T, Li H, Khare S et al (2015) High-throughput screening assay for the environmental water samples using cellular response profiles. Ecotoxicol Environ Saf 114:134-142

Peters MF, Lamore SD, Guo L, Scott CW, Kolaja KL (2015) Human stem cell-derived cardiomyocytes in cellular impedance assays: bringing cardiotoxicity screening to the front line. Cardiovasc Toxicol 15(2): 127-139

Pfeufer A, Jalilzadeh S, Perz S et al (2005) Common variants in myocardial ion channel genes modify the QT interval in the general population: results from the KORA study. Circ Res 96(6):693-701

Pouton CW, Haynes JM (2007) Embryonic stem cells as a source of models for drug discovery. Nat Rev Drug Discov 6(8):605-616

Pradhapan P, Kuusela J, Viik J, Aalto-Setala K, Hyttinen J (2013) Cardiomyocyte MEA data analysis (CardioMDA)-a novel field potential data analysis software for pluripotent stem cell derived cardiomyocytes. PLoS One 8(9):e73637

Priest BT, Bell IM, Garcia ML (2008) Role of hERG potassium channel assays in drug development. Channels 2(2):87-93

Qureshi ZP, Seoane-Vazquez E, Rodriguez-Monguio R, Stevenson KB, Szeinbach SL (2011) Market withdrawal of new molecular entities approved in the United States from 1980 to 2009. Pharmacoepidemiol Drug Saf 20(7):772-777

Recanatini M, Poluzzi E, Masetti M, Cavalli A, De Ponti F (2005) QT prolongation through $\mathrm{hERG} \mathrm{K}^{+}$) channel blockade: current 
knowledge and strategies for the early prediction during drug development. Med Res Rev 25(2):133-166

Redfern WS, Carlsson L, Davis AS et al (2003) Relationships between preclinical cardiac electrophysiology, clinical QT interval prolongation and torsade de pointes for a broad range of drugs: evidence for a provisional safety margin in drug development. Cardiovasc Res 58(1):32-45

Roy M, Dumaine R, Brown AM (1996) HERG, a primary human ventricular target of the nonsedating antihistamine terfenadine. Circulation 94(4):817-823

Sager PT, Gintant G, Turner JR, Pettit S, Stockbridge N (2014) Rechanneling the cardiac proarrhythmia safety paradigm: a meeting report from the Cardiac Safety Research Consortium. Am Heart J 167(3):292-300

Sager PT, Seltzer J, Turner JR et al (2015) Cardiovascular Safety Outcome Trials: a meeting report from the Cardiac Safety Research Consortium. Am Heart J 169(4):486-495

Sanchez-Chapula JA, Navarro-Polanco RA, Culberson C, Chen J, Sanguinetti MC (2002) Molecular determinants of voltagedependent human ether-a-go-go related gene (HERG) $\mathrm{K}^{+}$channel block. J Biol Chem 277(26):23587-23595

Sanchez-Chapula JA, Ferrer T, Navarro-Polanco RA, Sanguinetti MC (2003) Voltage-dependent profile of human ether-ago-go-related gene channel block is influenced by a single residue in the S6 transmembrane domain. Mol Pharmacol 63(5):1051-1058

Sanguinetti MC, Tristani-Firouzi M (2006) hERG potassium channels and cardiac arrhythmia. Nature 440(7083):463-469

Scheel O, Frech S, Amuzescu B, Eisfeld J, Lin KH, Knott T (2014) Action potential characterization of human induced pluripotent stem cell-derived cardiomyocytes using automated patch-clamp technology. Assay Drug Dev Technol 12(8):457-469

Schmitt N, Grunnet M, Olesen SP (2014) Cardiac potassium channel subtypes: new roles in repolarization and arrhythmia. Physiol Rev 94(2):609-653

Scott CW, Zhang X, Abi-Gerges N, Lamore SD, Abassi YA, Peters MF (2014) An impedance-based cellular assay using human iPSC-derived cardiomyocytes to quantify modulators of cardiac contractility. Toxicol Sci 142(2):331-338

Simpson JM, Maxwell D, Rosenthal E, Gill H (2009) Fetal ventricular tachycardia secondary to long QT syndrome treated with maternal intravenous magnesium: case report and review of the literature. Ultrasound Obstet Gynecol 34(4):475-480

Sirenko O, Hesley J, Rusyn I, Cromwell EF (2014) High-content high-throughput assays for characterizing the viability and morphology of human iPSC-derived neuronal cultures. Assay Drug Dev Technol 12(9-10):536-547

Splawski I, Timothy KW, Sharpe LM et al (2004) Ca(V)1.2 calcium channel dysfunction causes a multisystem disorder including arrhythmia and autism. Cell 119(1):19-31

Splawski I, Timothy KW, Decher N et al (2005) Severe arrhythmia disorder caused by cardiac L-type calcium channel mutations. Proc Natl Acad Sci USA 102(23):8089-8096 (discussion 8086-8)

Stansfeld PJ, Gedeck P, Gosling M, Cox B, Mitcheson JS, Sutcliffe MJ (2007) Drug block of the hERG potassium channel: insight from modeling. Proteins 68(2):568-580

Steffensen AB, Refsgaard L, Andersen MN et al (2015) IKs Gain- and loss-of-function in early-onset lone atrial fibrillation. J Cardiovasc Electrophysio 26(7):715-723

Stoelzle S, Haythornthwaite A, Kettenhofen R et al (2011) Automated patch clamp on mESC-derived cardiomyocytes for cardiotoxicity prediction. J Biomol Screen 16(8):910-916
Su X, Young EW, Underkofler HA, Kamp TJ, January CT, Beebe DJ (2011) Microfluidic cell culture and its application in highthroughput drug screening: cardiotoxicity assay for hERG channels. J Biomol Screen 16(1):101-111

Tang W, Kang J, Wu X et al (2001) Development and evaluation of high throughput functional assay methods for HERG potassium channel. J Biomol Screen 6(5):325-331

Tester DJ, Kopplin LJ, Will ML, Ackerman MJ (2005) Spectrum and prevalence of cardiac ryanodine receptor (RyR2) mutations in a cohort of unrelated patients referred explicitly for long QT syndrome genetic testing. Heart Rhythm 2(10):1099-1105

Thomas SH, Higham PD, Hartigan-Go K et al (1995) Concentration dependent cardiotoxicity of terodiline in patients treated for urinary incontinence. Br Heart J 74(1):53-56

Villoutreix BO, Taboureau O (2015) Computational investigations of hERG channel blockers: new insights and current predictive models. Adv Drug Deliv Rev 86:72-82

Wang T, Hu N, Cao J, Wu J, Su K, Wang P (2013) A cardiomyocytebased biosensor for antiarrhythmic drug evaluation by simultaneously monitoring cell growth and beating. Biosens Bioelectron 49:9-13

Wang Y, Suzek T, Zhang J et al (2014) PubChem BioAssay: 2014 update. Nucleic Acids Res 42(Database issue):D1075-D1082

Weissman NJ, Tighe JF Jr, Gottdiener JS, Gwynne JT (1998) An assessment of heart-valve abnormalities in obese patients taking dexfenfluramine, sustained-release dexfenfluramine, or placebo. Sustained-Release Dexfenfluramine Study Group. N Engl J Med 339(11):725-732

Wible BA, Hawryluk P, Ficker E, Kuryshev YA, Kirsch G, Brown AM (2005) HERG-Lite: a novel comprehensive high-throughput screen for drug-induced hERG risk. J Pharmacol Toxicol Methods 52(1):136-145

Wilhelms M, Rombach C, Scholz EP, Dossel O, Seemann G (2012) Impact of amiodarone and cisapride on simulated human ventricular electrophysiology and electrocardiograms. Europace 14(Suppl 5):v90-v96

Witchel HJ, Hancox JC, Nutt DJ (2003a) Psychotropic drugs, cardiac arrhythmia, and sudden death. J Clin Psychopharmacol 23(1):58-77

Witchel HJ, Hancox JC, Nutt DJ, Wilson S (2003b) Antipsychotics, HERG and sudden death. Br J Psychiatry 182:171-172

Xi B, Wang T, Li N et al (2011) Functional cardiotoxicity profiling and screening using the xCELLigence RTCA Cardio System. J Lab Autom 16(6):415-421

Xia M, Shahane SA, Huang R et al (2011) Identification of quaternary ammonium compounds as potent inhibitors of $\mathrm{hERG}$ potassium channels. Toxicol Appl Pharmacol 252(3):250-258

Zaniboni M, Pollard AE, Yang L, Spitzer KW (2000) Beat-to-beat repolarization variability in ventricular myocytes and its suppression by electrical coupling. Am J Physiol Heart Circ Physiol 278(3):H677-H687

Zeng H, Penniman JR, Kinose F et al (2008) Improved throughput of PatchXpress hERG assay using intracellular potassium fluoride. Assay Drug Dev Technol 6(2):235-241

Zhang H, Zou B, Yu H et al (2012) Modulation of hERG potassium channel gating normalizes action potential duration prolonged by dysfunctional KCNQ1 potassium channel. Proc Natl Acad Sci USA 109(29):11866-11871

Zhou Z, Vorperian VR, Gong Q, Zhang S, January CT (1999) Block of HERG potassium channels by the antihistamine astemizole and its metabolites desmethylastemizole and norastemizole. J Cardiovasc Electrophysiol 10(6):836-843 